\title{
The Effect of Short-Toothed and Dalmatian Sage Extracts on Platelet Aggregation
}

\author{
Andrea Antolić , Željan \\ Maleš², Maja Tomičić ${ }^{3}$ \\ and Mirza Bojićc* \\ 'University of Zagreb, Faculty of \\ Science, Roosevelt Square 6, HR- \\ 10000 Zagreb, Croatia \\ 'University of Zagreb, Faculty of \\ Pharmacy and Biochemistry, \\ Department of Pharmaceutical \\ Botany, Schrottova 39, HR-10000 \\ Zagreb, Croatia \\ ${ }^{3}$ Croatian Institute of Transfusion \\ Medicine, Department of Platelet and \\ Leukocyte Immunology, Petrova 6, \\ HR-10000 Zagreb, Croatia \\ ${ }^{4}$ University of Zagreb, Faculty of \\ Pharmacy and Biochemistry, \\ Department of Medicinal Chemistry, \\ A. Kovačića 1, HR-10000 Zagreb, \\ Croatia
}

Received: 16 August 2017 Accepted: 15 December 2017
*Corresponding author:

Phone: +38514818304;

Fax: +38516394400;

E-mail:mbojic@pharma.hr

ORCID IDs: 0000-0002-1843-0776 (Antolić), 0000-0003-1034-2525 (Maleš), 0000-0001-9289-4168 (Tomičić), 0000-0002-8381-9577 (Bojić)

\section{SUMMARY}

Sage (Salvia sp.) is a genus of a native Mediterranean plant used for aromatization of foods. In this study, total polyphenolic profile, antioxidant properties and antiplatelet effect of short-toothed sage (Salvia brachyodon Vandas) are analyzed and compared to most commonly used Salvia species (S. officinalis, Dalmatian sage). Content of total flavonoids was $0.08-0.23 \%$ and of phenolic acids $0.47-3.04 \%$. Antioxidant DPPH assay showed higher antioxidant capacity of S. brachyodon $(29-36 \mathrm{mg} / \mathrm{mL}$ of gallic acid equivalents) than of S. officinalis. In functional test of primary haemostasis, extracts of $S$. brachyodon have prevented platelet aggregation in nanomolar concentration $(21 \mathrm{nM})$, thus showing potential in prevention of thrombus formation as functional food or dietary supplement. Antiplatelet activity was related to antioxidant capacity $(r=0.7014, \mathrm{p}=0.0352)$ indicating that prevention of aggregation is not caused by an individual component, but it is rather a result of synergistic effect of polyphenols. The obtained results are preliminary and a more detailed study of the possibility of applying the investigated plant species as supplements for the prevention of the problem of cardiovascular system and platelet aggregation is needed.

Key words: sage, flavonoids, phenolic acids, platelet aggregation

\section{INTRODUCTION}

Sage (genus Salvia L., Lamiaceae family) is an aromatic plant known for the content of the essential oil. Lately, polyphenols found in sage have been in focus of study due to their antioxidant and antimicrobial properties (1). Flavonoids, major polyphenols alongside phenolic acids, have been extensively studied for their protective role in prevention of thrombosis. Previous studies have shown that flavonoids have a potential to influence primary haemostasis, i.e. platelet aggregation in submicromolar concentrations in a similar manner as acetylsalicylic acid (aspirin) and clopidogrel $(2,3)$. Thus, extension of studies to herbal drugs seems a logical continuation. European pharmacopoeia lists these plant drugs as rich in flavonoids: Agni casti fructus, Arnicae flos, Aurantii amari flos, Calendulae flos, Ginkgonis folium, Matricariae flos, Myrtilli fructus recens, Sambuci flos, Silybi mariani fructus, etc. (4).

One of the major reasons why the focus is on antiplatelet activity of polyphenols is because of their influence on cardiovascular diseases, which are leading causes of death in Western countries, creating a huge burden for health care system (5). While many drugs are used for treatment and prevention, there is no ideal drug, making this area of research still attractive for scientists and pharmaceutical industry. Polyphenols have been shown to have beneficial effects on human health (6). In Europe, resveratrol has been related to decrease in the incidence of cardiovascular diseases in fat-rich diet (French paradox), while in Asia green tea polyphenols have been attributed to protective role in rice- and carbohydrate-rich diet (Asian paradox) (7).

In this study, we focus on short-toothed sage (Salvia brachyodon Vandas), an endemic species that grows in the south east areas of the Adriatic coast in Croatia, Bosnia and Herzegovina, and Montenegro. It is a perennial plant that grows up to $70-80 \mathrm{~cm}$ in height and flowers from July to September. Leaves are 6-14 cm long, $1.5-4 \mathrm{~cm}$ wide, with long petiole. Panicula is composed of few flowers that are on long lateral branches. Morphologically and 
genetically, S. brachyodon belongs to a group of Dalmatian sages (S. officinalis), to which results of chemical analysis and platelet aggregation assays were compared (8).

Herbal drugs of Salvia sp. contain aerial parts - mainly leaves, and are used due to their high content of polyphenols. There are no reports on the content of flavonoids and phenolic acids of short-toothed sage (S. brachyodon) nor antioxidant potential or possible antiplatelet activity of extracts. Thus, the objective of this study is to determine total flavonoids, antioxidant potential and the effect of short-toothed sage primary haemostasis in platelet aggregation test. As S. brachyodon is closely related to the well-studied Salvia species S. officinalis, the latter was selected for comparison. Analyzed samples of S. brachyodon were collected in 2015 and 2016 to minimize the effect of environmental factors.

\section{MATERIALS AND METHODS}

\section{Materials}

All chemical standards were purchased from Sigma-Aldrich, Merck (St. Louis, MO, USA) and organic solutions from Kemika (Zagreb, Croatia). Plant material samples of Salvia brachyodon were collected at locations close to the city of Orebić, Croatia. Samples of S. officinalis were obtained from Suban (Strmec, Croatia) and Pharmaceutical Botanical Garden Fran Kušan (Zagreb, Croatia). Voucher specimens are deposited in the Herbarium of the Department of Pharmaceutical Botany, University of Zagreb, Croatia.

\section{Determination of total phenolic acids and flavonoids}

Total content of flavonoids was determined by Christ-Müller's method (9) and phenolic acids according to European Pharmacopoeia $(10,11)$. A mass of $0.3 \mathrm{~g}$ of herbal drug was extracted with $20 \mathrm{~mL}$ of acetone, $2 \mathrm{~mL}$ of $25 \% \mathrm{HCl}$ and $1 \mathrm{~mL}$ of $0.5 \%$ aqueous solution of hexamethylenetetramine for 30 min under reflux. Thus, total flavonoids were determined after acid hydrolysis as liberated aglycones spectrophotometrically (model Varian Cary 50; Agilent Technologies, Santa Clara, CA, USA) at $425 \mathrm{~nm}$ in the form of complex of flavonoids with aluminum in a methanol-ethyl acetate-acetic acid medium. Percentage of total flavonoids was obtained based on the formula:

$$
w(\text { flavonoid })=0.772 \cdot A / m
$$

where $A$ is measured absorbance and $m$ is mass of sample used in the analysis (10).

For the purpose of total phenolic acid determination, $0.2 \mathrm{~g}$ of herbal drug was extracted with $200 \mathrm{~mL}$ of $50 \%$ ethanol for $30 \mathrm{~min}$ in the boiling water bath. Total phenolic acids were determined by measuring the absorbance at $505 \mathrm{~nm}$ (spectrophotometer Varian Cary 50; Agilent Technologies) of the complex formed between phenolic acids and sodium molybdate-sodium nitrite as an equivalent of rosmarinic acid. Percentage of phenolic acids was calculated based on the formula:

$$
w(\text { phenolic acid })=0.5 \cdot \mathrm{A} / \mathrm{m}
$$

where $A$ is measured absorbance and $m$ is mass of sample used in the analysis (11).

Ethanolic extracts used for total phenolic acid determination were also used for DPPH test. Acetone extracts obtained in total flavonoid analysis were dried and dissolved in dimethyl sulfoxide (DMSO) for platelet aggregation test.

\section{DPPH test}

$\mathrm{DPPH}$ is a stable violet-coloured free radical that exhibits a high absorption value at $518 \mathrm{~nm}$. In the presence of a free radical scavenger, e.g. polyphenols, the concentration of DPPH radical is reduced. Reduction can be monitored by a degree of decolourization. DPPH was prepared as $0.3 \mathrm{mM}$ methanol solution. Working solution was prepared by dilution with methanol to obtain absorbance of 0.8 (12).

Gallic acid was used as standard antioxidant to obtain a calibration curve with the following solution concentrations: $0.01,0.02,0.04,0.08,0.16,0.32,0.5,0.625,1.0,1.25,2.0,2.5$ and $5.0 \mathrm{mg} / \mathrm{mL}$.

A volume of $2 \mathrm{~mL}$ of sample extract or standard solution was mixed with $10 \mu \mathrm{L}$ of DPPH reagent. Absorbance was measured at $518 \mathrm{~nm}$ using spectrophotometer Varian Cary 50 (Agilent Technologies) after $15 \mathrm{~min}$. All measurements were performed in triplicate.

\section{Platelet aggregation functional test}

This study was approved by Ethical Committee of Croatian Institute of Transfusion Medicine, Zagreb, Croatia. A total number of 10 volunteers participated in this research. All volunteers gave informed written consent. Freshly taken citrated blood was used for the measurement of aggregation; three different healthy volunteers per sample to minimize biological variability.

Platelet aggregation was analyzed by Multiplate ${ }^{\circledR}$ analyzer (Roche, Switzerland). Routine analysis procedure was used: $300 \mu \mathrm{L}$ of citrated blood were incubated for 6 min with $20 \mu \mathrm{L}$ of extract solution and $300 \mu \mathrm{L}$ of calcium chloride saline physiological solution preheated at $37^{\circ} \mathrm{C}$. For negative control (untreated sample), $20 \mu \mathrm{L}$ of solvent, i.e. DMSO was used (final volume fraction in all experiments was below $3 \%$ ). Aggregation cascade was initiated by the addition of $20 \mu \mathrm{L}$ of adenosine diphosphate reagent (ADP). Aggregation was measured for $6 \mathrm{~min}$ and expressed as area under curve in arbitrary units (AU) (3).

For platelet aggregation analysis, extracts were dried. Based on the dry mass and molar mass of quercetin, concentration of samples in platelet assays was expressed in nM. Quercetin molar mass was selected arbitrarily as it is one of the most commonly used flavonoids for in vitro experiments. The results of platelet aggregation test were expressed as minimal antiaggregatory concentration (MINaAC). This value presents the lowest concentration of sample that can cause statistically significant reduction of aggregation when compared to the untreated sample. The lower the values of 
$\mathrm{MINaAC}$, the stronger the antiaggregatory effect. Procedure for determination of MINaAC was based on procedure of Bojić et al. (2).

Pearson's correlation coefficients between MINaAC values, content of total flavonoids, phenolic acids and DPPH antioxidant test as well as their statistical significance were calculated using Social Science Statistics online software (13).

\section{RESULTS AND DISCUSSION}

\section{Flavonoid and phenolic acid content and antioxidant capacity}

Results of spectrophotometric determinations of flavonoids and phenolic acids and antioxidant capacity are shown in Table 1. Content of flavonoids of Salvia brachyodon leaf samples determined by Christ-Müller method (9) was comparable to that of commercially obtained and cultivated samples of S. officinalis: $0.19-0.21$ vs. $0.14-0.23 \%$. It is interesting to notice that the highest content of phenolic acids was observed in S. brachyodon leaves. Results of the DPPH test were related to the content of the phenolic acids in leaves; both leaves of S. brachyodon and S. officinalis had higher content of phenolic acids (1.21-3.04 \%) and higher values of DPPH as GAE (20-36 mg/mL) than stem and flower samples (0.47-0.74 $\%$ and $15-16 \mathrm{mg} / \mathrm{mL}$, respectively).

While flavonoid content can be as high as 1-5 \% (14) with ultrasound and microwave-assisted extraction, lower values are observed using conventional heat-assisted extraction. Results obtained with S. brachyodon (0.08-0.21\%) are comparable to those obtained with S. mirzayanii (0.01-0.12 \%) (15). Content of flavonoids is comparable to other Salvia sp. that have been studied by Miliauskas et al. (16), who also observed similar values of antioxidant capacity. In their study, the content of total polyphenols (flavonoids and phenolic acids, 0.9-2.4\%) was up to ninefold greater than the content of flavonoids (0.1-0.6\%) as it is the case in our study (total polyphenols $0.70-3.04 \% \mathrm{vs}$. flavonoids 0.12-0.23\%). Generalić et al. (1) found that rosmarinic acid was the most abundant phenolic acid in Dalmatian sage, while most abundant flavonoid aglycone was quercetin.

\section{Antiaggregatory effect}

Results of platelet aggregation assay for leaf samples are shown in Fig. 1. Leaf samples of S. officinalis cultivated in botanical garden Fran Kušan and Biokovo, Croatia, showed the strongest antiaggregatory effect, i.e. the lowest MINaAC of 21 $\mathrm{nM}$. These samples are the richest in flavonoids (0.21-0.23\%). S. brachyodon leaf sample from 2015 showed higher MINaAC value of $2.1 \mathrm{mM}$ than the leaf sample from 2016, which had MINaAC value of $0.21 \mathrm{mM}$.

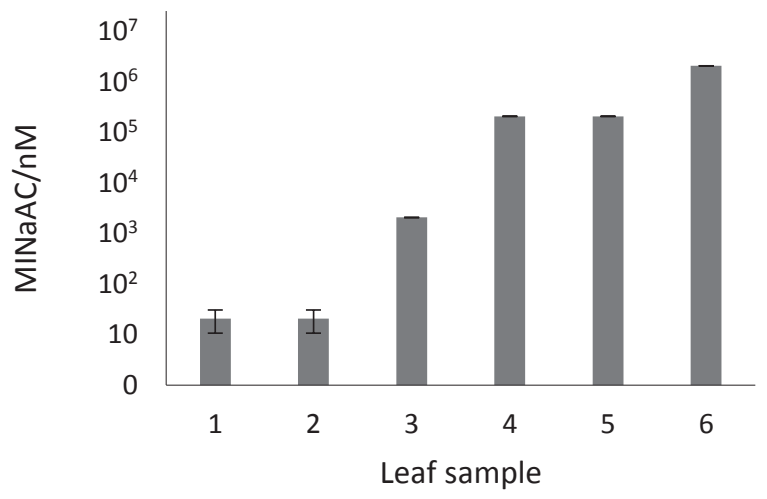

Fig. 1. Antiaggregatory effect of sage leaf samples. Aggregation is expressed as minimal antiaggregatory concentration (MINaAC) and is shown on logarithmic scale. Samples: $1=S$. officinalis from Biokovo, $2=S$. officinalis from Fran Kušan, $3=S$. officinalis from Suban, $4=S$. officinalis from Naturavita, $5=S$. brachyodon collected in 2016, $6=S$. brachyodon collected in 2015

Pearson's correlation coefficient between total flavonoids, total phenolic acids and DPPH test vs. MINaAC were 0.2469, 0.3487 and 0.7014 , respectively (Table 2 ). However, only antioxidant capacity was statistically related to antiplatelet activity ( $p=0.0352)$. While in some cases antiplatelet activity can be related to an individual component, e.g. rosmarinic acid in lemon balm (Melissa officinalis) due to high content of individual polyphenols (17), in this case it is more closely related to the antioxidant properties of polyphenols that underpin many biological properties (18).

Out of all samples of S. brachyodon (Fig. 2), flowers from 2016 had the highest antiaggregatory effect in nanomolar

Table 1. Content of flavonoids and phenolic acids, and the results of DPPH antioxidant test of Salvia samples

\begin{tabular}{clccc} 
No. & Sample & $w$ (flavonoid)/\% & $w$ (phenolic acid)/\% & $\gamma(\mathrm{DPPH}$ as GAE $) /(\mathrm{mg} / \mathrm{mL})$ \\
1 & S. brachyodon, leaf, 2015 & $0.19 \pm 0.01$ & $2.26 \pm 0.08$ & $36 \pm 7$ \\
2 & S. brachyodon, leaf, 2016 & $0.21 \pm 0.01$ & $3.04 \pm 0.15$ & $29 \pm 5$ \\
3 & S. brachyodon, flower, 2015 & $0.08 \pm 0.01$ & $0.74 \pm 0.03$ & $15 \pm 2$ \\
4 & S. brachyodon, flower, 2016 & $0.09 \pm 0.01$ & $0.70 \pm 0.03$ & $16 \pm 1$ \\
5 & S. brachyodon, stem, 2015 & $0.12 \pm 0.01$ & $0.47 \pm 0.02$ & $15 \pm 3$ \\
6 & S. officinalis, Fran Kušan, leaf, 2016 & $0.23 \pm 0.01$ & $2.22 \pm 0.08$ & $28 \pm 4$ \\
7 & S. officinalis, Suban, leaf, 2016 & $0.15 \pm 0.01$ & $2.18 \pm 0.03$ & $29 \pm 4$ \\
8 & S. officinalis, Biokovo, leaf, 2016 & $0.21 \pm 0.01$ & $1.21 \pm 0.01$ & $20 \pm 2$ \\
9 & S. officinalis, Naturavita, leaf, 2016 & $0.14 \pm 0.01$ & $1.24 \pm 0.03$ & $21 \pm 3$ \\
\hline
\end{tabular}

Results are expressed as mean value \pm standard deviation of triplicate measurements, GAE=gallic acid equivalent 
Table 2. Correlations between contents of flavonoids, phenolic acids, DPPH antioxidant test and antiplatelet activity (MINaAC)

\begin{tabular}{ccc} 
& DPPH test & MINaAC \\
Flavonoids & 0.5599 & 0.2469 \\
Phenolic acids & 0.6376 & 0.3487 \\
DPPH test & 1.000 & $0.7014^{*}$ \\
MINaAC & & 1.000 \\
\hline
\end{tabular}

*Statistically significant correlation $(p<0.05)$. MINaAC $=$ minimal antiaggregatory concentration

range $(21 \mathrm{nM})$. The highest values of MINaAC were observed in leaf samples.

When compared to standards of flavonoids that in the same experimental setup showed lowest values of MINaAC of $119 \mathrm{nM}$ (3,6-dihydroxyflavone and syringetin) (2), sixfold lower values of $S$. brachyodon extracts look promising in modulating platelet aggregation. This can be attributed to synergistic effect of flavonoid combinations due to their possible different mechanism of action (3).

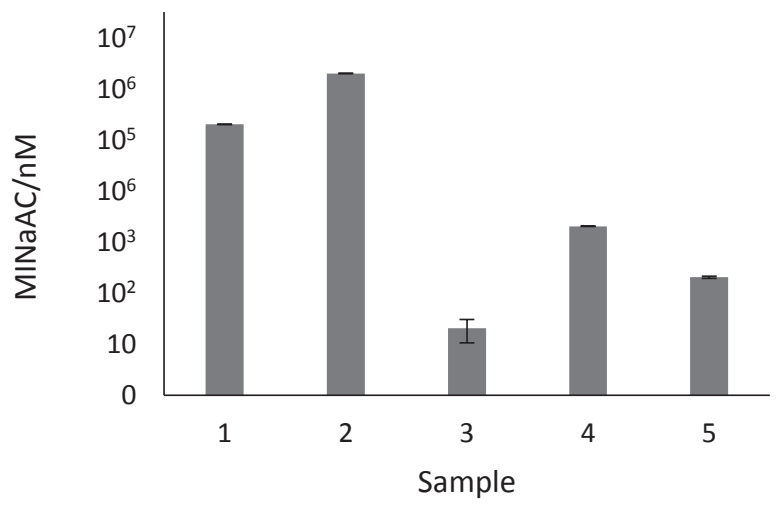

Fig. 2. Antiaggregatory effect of Salvia brachyodon samples. Aggregation is expressed as minimal antiaggregatory concentration (MINaAC) and is shown on logarithmic scale. Samples: 1=leaf 2016, 2=leaf 2015, 3=flower 2016, 4=flower 2015, 5=stem 2015

It should be noted that during the study of essential oil antiaggregatory effect, the influence of oil on platelet aggregation was not observed (19). This can be attributed to different chemical composition of oil in which terpenes are the main constituents.

\section{CONCLUSIONS}

To the best of our knowledge, this is a first report on total flavonoid and total phenolic acid contents, antioxidant capacity and antiplatelet effect of Salvia brachyodon. Nanomolar concentrations at which samples of Salvia species show antiaggregatory effect indicate its potential use as cardiovascular dietary supplement. Although there is a tendency to attribute biological activity to individual substance, this study shows that antiplatelet activity is to some extent related to the antioxidant capacity, indicating that prevention of aggregation is not caused by individual component, but rather is a result of synergistic effect of polyphenols and their antioxidant properties among others. The obtained results are preliminary and a more detailed study of the possibility of applying the investigated plant species as supplements for the prevention of the problem of cardiovascular system and platelet aggregation is needed.

\section{ACKNOWLEDGEMENTS}

We would like to thank V. Suban Jakuš and I. Trojanović for providing $S$. officinalis and S. brachyodon samples, respectively. This work was supported by University of Zagreb (Z1111-MB).

\section{REFERENCES}

1. Generalić I, Skroza D, Šurjak J, Smole Možina S, Ljubenkov I, Katalinić A, Šimat V, Katalinić V. Seasonal variations of phenolic compounds and biological properties in sage (Salvia officinalis L.). Chem Biodivers. 2012;9(2):441-57. https://doi.org/10.1002/cbdv.201100219

2. Bojić M, DebeljakŽ, Tomičić M, Medić-Šarić M, Tomić S. Evaluation of antiaggregatory activity of flavonoid aglycone series. Nutr J. 2011;10:73.

https://doi.org/10.1186/1475-2891-10-73

3. Bojić M, Debeljak Ž, Medić-Šarić $M$, Tomičić M. Interference of selected flavonoid aglycons in platelet aggregation assays. Clin Chem Lab Med. 2012;50(8):1403-8. https://doi.org/10.1515/cclm-2011-0960

4. Badal McCreath S, Delgoda R. Pharmacognosy: Fundamentals, applications and strategies. Cambridge, MA, USA: Academic Press; 2017.

5. American Heart Association Statistics Committee and Stroke Statistics Subcommittee. Heart disease and stroke statistics - 2017 update: A report from the American Heart Association. Circulation. 2017;135(10):e146-603. https://doi.org/10.1161/CIR.0000000000000485

6. Manach $C$, Scalbert $A$, Morand $C$, Rémésy $C$, Jiménez $L$. Polyphenols: Food sources and bioavailability. Am J Clin Nutr. 2004;79(5):727-47. https://doi.org/10.1093/ajcn/79.5.727

7. Catalgol B, Batirel S, Taga Y, Ozer NK. Resveratrol: French paradox revisited. Front Pharmacol. 2012;3:Article No 141. https://doi.org/10.3389/fphar.2012.00141

8. Radosavljević I, Satovic Z, Liber Z. Causes and consequences of contrasting genetic structure in sympatrically growing and closely related species. AoB Plants. 2015;7:plv106. https://doi.org/10.1093/aobpla/plv106

9. Christ B, Müller KH. Determination of the amount of flavonol derivatives in drugs. Arch Pharm. 1960;293(12):1033-42 (in German). https://doi.org/10.1002/ardp.19602931202

10. European Pharmacopoeia. Strasbourg, France: Council of Europe; 2007.

11. Medić-Šarić M, Bojić M, Rastija V, Cvek J. Polyphenolic profiling of Croatian propolis and wine. Food Technol Biotechnol. 2013;51(2):159-70. 
12. Jasprica I, Bojic M, Mornar A, Besic E, Bucan K, Medic-Saric M. Evaluation of antioxidative activity of Croatian propolis samples using $\mathrm{DPPH}^{\circ}$ and $\mathrm{ABTS}^{\circ+}$ stable free radical assays. Molecules. 2007;12(5):1006-21. https://doi.org/10.3390/12051006

13. Social Science Statistics software. 2017. Available from: http://www.socscistatistics.com.

14. Zeković Z, Pintać D, Majkić T, Vidović S, Mimica-Dukić N, Teslić $\mathrm{N}$, et al. Utilization of sage by-products as raw material for antioxidants recovery - Ultrasound versus microwave-assisted extraction. Ind Crops Prod. 2017;99:49-59. https://doi.org/10.1016/j.indcrop.2017.01.028

15. Moein MR, Moein S, Ahmadizadeh S. Radical scavenging and reducing power of Salvia mirzayanii subfractions. Molecules. 2008;13(11):2804-13.

https://doi.org/10.3390/molecules13112804
16. Miliauskas G, Venskutonis PR, van Beek TA. Screening of radical scavenging activity of some medicinal and aromatic plant extracts. Food Chem. 2004;85(2):231-7. https://doi.org/10.1016/j.foodchem.2003.05.007

17. Maleš Ž, Antolić A, Babić I, Jurić S, Bojić M. Quantitative analysis of phenolic acids and antiplatelet activity of Melissa officinalis leaf extracts. Nat Prod Commun. 2017;12(1):93-4.

18. Havsteen $\mathrm{BH}$. The biochemistry and medical significance of the flavonoids. Pharmacol Ther. 2002;96(2-3):67-202. https://doi.org/10.1016/S0163-7258(02)00298-X

19. Yen HF, Wang SY, Wu CC, Lin WY, Wu TY, Chang FR, Wang CK. Cytotoxicity, anti-platelet aggregation assay and chemical components analysis of thirty-eight kinds of essential oils. J Food Drug Anal. 2012;20(2):478-83. https://doi.org/10.6227/jfda.2012200207 